Check for updates

Cite this: RSC Adv., 2018, 8, 567

Received 19th October 2017

Accepted 15th December 2017

DOI: $10.1039 / c 7 r a 11578 d$

rsc.li/rsc-advances

\section{Insights into thermal reduction of the oxidized graphite from the electro-oxidation processing of nuclear graphite matrix $\dagger$}

\author{
Gengyu Zhang, Mingfen Wen, ${ }^{*}$ Shuwei Wang, Jing Chen and Jianchen Wang (D) *
}

Electro-oxidation disintegration is a potential technology pathway to detach graphite waste from high-level radioactive wastes in the spent fuel reprocessing of high temperature gas cooled reactors (HTGR). But this electrochemical treatment can introduce oxygen functional groups into the graphite lattice. Further disposal will require the development of safe and cost-effective methods to achieve the reduction and deoxygenation of the oxidized graphite wastes. In general, oxygen species can be removed from oxidized graphite directly in an easy-to-operate way by thermal annealing. In this paper, the thermal reduction process of oxidized graphite from the electro-oxidation processing of graphite matrix from simulative element of HTGR was researched. The thermodynamic state and kinetic process of the deoxygenation reaction of electrolytic graphite oxide (EGO) have also been investigated for better understanding of the reduction mechanism. According to thermal analysis results, the oxygen functional groups were removed mostly between $160{ }^{\circ} \mathrm{C}$ and $250{ }^{\circ} \mathrm{C}$, and the main weight loss of EGO during thermal annealing was caused by evolved volatile gases $\left(\mathrm{CO}_{2}, \mathrm{CO}\right.$ and $\left.\mathrm{H}_{2} \mathrm{O}\right)$. The activation energy of deoxygenation reaction for $\mathrm{EGO}$ is calculated to be $115.6 \mathrm{~kJ} \mathrm{~mol}^{-1}(1.20 \mathrm{eV}$ per atom). And the persistent residual oxygen species on reduced EGO (REGO) is determined to be from two parts, i.e. the stubborn built-in oxygen species of pristine nuclear graphite and the newly formed $\mathrm{C}-\mathrm{O}$ moieties on the basal plane of graphite sheet during thermal annealing process. In addition, an attempt was also made to elucidate how the thermal treatment acted on the electronic structure of EGO. Meanwhile, the mechanism of dissociation of oxygen species $(-\mathrm{OH}, \mathrm{C}-\mathrm{O}-\mathrm{C}, \geq \mathrm{C}=\mathrm{O},-\mathrm{COOH})$ on the thermal reduction of oxidized graphite has been suggested in this paper.

\section{Introduction}

In the nuclear industry, graphite has been widely utilized in HTGR where graphite and carbon materials are used for in-core structural components, such as fuel blocks, reflectors, core support structures and a fuel element matrix material. ${ }^{1-4}$ Hence, the decommissioning of HTGR will produce a large amount of irradiated graphite waste. In recent years, electro-oxidation method with salts as electrolyte has been developed for the separation of the graphite matrix from simulated spent fuel elements of HTGR in Institute of Nuclear and New Energy Technology (INET), Tsinghua University. ${ }^{5-7}$ The so-called "electrochemical disintegration" method has been achieved using graphite matrix as an anode and inert counter electrode in concentrated nitrates, sulfates, phosphates, sulphuric acid and nitric acid. Results showed that the graphite matrix could be

Institute of Nuclear and New Energy Technology, Tsinghua University, Beijing 100084, China. E-mail: wangjianchen@mail.tsinghua.edu.cn; wenmingfen@mail.tsinghua. edu.cn; Tel: $+8613910738328 ;+8613910638139$

$\dagger$ Electronic supplementary information (ESI) available. See DOI: $10.1039 / \mathrm{c} 7 \mathrm{ra} 11578 \mathrm{~d}$ detached from spent fuel elements effectively and the dissolution of the fuel kernel could be avoided in this process. ${ }^{6,7}$

However, the electro-oxidation process may induce oxygencontaining groups into the graphite structure, and lead to the conversion of $\mathrm{sp}^{2}$ carbon atoms into $\mathrm{sp}^{3}$ ones. And the oxidized graphite is widely regarded as an energetic material which undergoes explosive decomposition if heated. ${ }^{8-10}$ Thus, the oxygen-rich derivative of graphite from the electrochemical process exhibits a weak chemical-stability. These reactive features represent important safety concerns in industry that makes further processing more difficult. To increase the stability of the graphite waste and make it safer in reprocessing, storing or disposal, the very first thing is to remove the oxygen species from the graphite backbone. It has been well demonstrated in previous researches that oxidized graphite can be deoxygenated by thermal annealing, chemical reduction or photo-reduction. ${ }^{11-15}$ However, both chemical reduction and photo-reduction suffers from a relatively low $\mathrm{C} / \mathrm{O}$ element content, with a sizeable amount of residual oxygen species. In comparison, thermal treatment is considered as the most simple and cost-effective method to achieve the reduction \& deoxygenation of oxidized graphite with no introduction of any 
impurities. In thermal reduction process, oxygen species of graphite oxide decompose exothermically upon heating, and produce a gas mainly composed of $\mathrm{H}_{2} \mathrm{O}$, $\mathrm{CO}$, and $\mathrm{CO}_{2} \cdot{ }^{12,16,17}$ Thermal "reduction" is actually a thermolysis or pyrolysis process. Technically, it should not be called a reduction process since there is no external reductant participation in reaction. Instead, it is more like a chemical disproportionation reaction, in which the original carbon atoms are decomposed into reduced forms in solid reduced graphite oxide and oxidized forms that are primarily consisted of carbonous gas-phase (i.e. $\mathrm{CO}, \mathrm{CO}_{2}$ ).

In addition, thermal reduction of oxidized graphite is a common processing step in the fabrication of many graphenerelated materials and devices. Currently, many researches are focused on the application of graphite oxide and on the materials obtained by its modification (e.g. thermally modified graphene oxide). And the thermal behavior of graphite oxide prepared by traditional methods (Staudenmaier, Hofmann and Hummers methods) has been extensively investigated. ${ }^{\mathbf{1 2 1 8 - 2 0}}$ These researches can help us understand the thermal treatment process of oxidized graphite from the electro-oxidation processing of simulated nuclear graphite matrix.

However, the detailed mechanisms of the thermal reduction process of EGO stay unclear, and the thermal behavior of graphite oxide prepared by electrochemical methods has rarely been investigated. Therefore, it is highly desirable to understand the thermal reduction process and to be able to provide new guides for controlling the properties of resulting reduction product.

In this work, we strive to give a comprehensive thermal analysis of EGO in inert atmosphere. Meanwhile, we compared the thermal stability of the pristine nuclear graphite and EGO in two different atmospheres. The material's structural evolution during the thermal treatment in inert nitrogen atmosphere was investigated using X-ray diffraction (XRD), X-ray photoelectron spectroscopy (XPS), scanning electron microscopy (SEM), transmission electron microscopy (TEM), and selected area electron diffraction (SAED). These results can make us get a better understanding of the physical and chemical properties of electrochemical oxidized nuclear-grade graphite and offer us the guide for applying the thermal methods to the reduction of EGO from the reprocessing procedure of HTGR. Combining these analytical results and concluding from the previous research, we discussed the implications of thermal treatment for safe EGO processing. And at last, an explanation of reduction mechanism of the thermal process and a formation pathway of the evolved gases were proposed.

\section{Experimental}

\subsection{Material}

2.1.1 Starting material. The simulative graphite matrix ball (calcined at $800{ }^{\circ} \mathrm{C}$, pressed under $300 \mathrm{MPa}$ without fuel particles), fabricated with a reactor-grade graphite material manufactured by Institute of INET of Tsinghua University was used as the initial graphitic material. The graphite anode used in the preparation experiment of electrolytic graphite oxide was fabricated from the graphite ball, and the pristine graphite (PG) used in the thermal analysis and characterization is made by the mechanical grinding of this graphite matrix.

2.1.2 Electrolytic graphite oxide (EGO). The electrochemical disintegration method used to prepare the electrolytic graphite oxide was derived from the method used by Tian previously. ${ }^{6,7}$ The cuboid graphite plates shaped from the simulative spherical fuel elements (graphite matrix ball) used as the anode and stainless-steel electrode was adopted as the cathode. The electrolyte solution was prepared from analytically pure $\mathrm{NaNO}_{3}$ dissolved in deionized water. Electrolytic experiments were carried out at constant current in electrolytic cell using a DC power supply. During the electrolytic process, the constant current between the two electrodes was set to $20 \mathrm{~A}$, the $\mathrm{pH}$ of electrolyte was maintained around 3 , and the concentration of $\mathrm{NaNO}_{3}$ was controlled at about $4 \mathrm{~mol} \mathrm{~L}^{-1}$. The entire electrolytic process lasted about an hour. After electro-oxidation process, the electrolytic product was filtered, washed several times, then dried under vacuum at room temperature and stored in the presence of desiccant.

2.1.3 Thermally-treated EGO. The as-prepared oxidized graphite from the electrochemical disintegration process was then subjected to thermal treatment. The thermal annealing reduction of EGO was performed at predetermined intervals of temperature $\left(50{ }^{\circ} \mathrm{C}, 100{ }^{\circ} \mathrm{C}, 150{ }^{\circ} \mathrm{C}, 200{ }^{\circ} \mathrm{C}, 300{ }^{\circ} \mathrm{C}, 500{ }^{\circ} \mathrm{C}\right.$, $800{ }^{\circ} \mathrm{C}, 1000{ }^{\circ} \mathrm{C}$ ) under a nitrogen atmosphere in a alundum crucible reactor. After reaching the temperature of the furnace, the samples were maintained at that temperature for not less than $5 \mathrm{~min}$. Then, the heat stopped and the samples cooled slowly and naturally below $30{ }^{\circ} \mathrm{C}$ to convert in inert atmosphere. The resulting oxidized graphite were coded as REGO- $100{ }^{\circ} \mathrm{C}$, REGO-150 ${ }^{\circ} \mathrm{C}$, REGO-200 ${ }^{\circ} \mathrm{C}$, REGO-300 ${ }^{\circ} \mathrm{C}$, REGO-500 ${ }^{\circ} \mathrm{C}$, REGO-800 ${ }^{\circ} \mathrm{C}$ and REGO- $1000{ }^{\circ} \mathrm{C}$ respectively, in the following text. After thermal treatment, the products were used for analysis by different characterization techniques.

\subsection{Characterization}

2.2.1 Thermal analysis. Thermogravimetric analysis (TGA) experiments in dynamic mode were carried out on Shimadzu TGA-50. Measurements were made in nitrogen or air atmosphere at the rate of $10{ }^{\circ} \mathrm{C} \mathrm{min}^{-1}$ from room temperature to $1000{ }^{\circ} \mathrm{C}$ with the sample amount of $5 \mathrm{mg}$ (accuracy of $0.001 \mathrm{mg}$ ). The DSC measurements were performed in inert nitrogen atmosphere using the same instrument with a sample amount of approximately $5 \mathrm{mg}$. The samples were heated to $1000^{\circ} \mathrm{C}$ at several different heating rates.

TGA/MS experiment was carried out using another instrument (TGA Q500), different from the previous one. It was coupled to a Pfeiffer Vacuum Thermo-Star mass spectrometer equipped with a channeltron detector. This experiment was recorded under constant nitrogen flow of $100 \mathrm{~mL} \mathrm{~min}^{-1}$.

2.2.2 Morphology and structure. The product after thermal treatment was characterized using XRD, XPS, SEM, TEM, SAED.

XRD patterns of the samples were collected using an advance diffractometer (D8, Bruker, Germany) equipped with a $\mathrm{Cu}-\mathrm{K} \alpha$ radiation, at steps of $0.02^{\circ}$, and with a scan range between $10^{\circ}$ and $80^{\circ}$. 
SEM micrographs were recorded using a Merlin FESEM equipped with an energy-dispersive X-ray spectrometer at $50 \mathrm{kV}$. Energy dispersive X-ray spectroscopy (EDX) was applied to monitor the major element composition of the oxidized graphite and its thermal reduction products.

TEM measurements were conducted with a TECNAIG2 20 microscope at an acceleration voltage of $300 \mathrm{kV}$. Meanwhile, SAED pattern was performed using the TEM instrument, and the electron beam size was set to about $500 \mathrm{~nm}$.

XPS analyses were done with a PHI Quantera SXM spectrometer equipped with a monochromatized $\mathrm{Al} \mathrm{K} \alpha \mathrm{X}$-ray source. And XPS peak software was used for data processing and analysis, in which Gaussian-Lorentzian waveforms were used to fit $\mathrm{C}$ 1s and $\mathrm{O}$ 1s core-level spectra after deducting a Shirley background.

Nitrogen adsorption/desorption isothermal analysis was measured by using BEL mini-instrument, and the specific surface area was obtained by Brunauer Emmett Teller (BET) analyses of the adsorption isotherm. All surface area values were recorded only when linear BET correlation factor was at least $R^{2}=0.9999$.

\section{Results and discussions}

\subsection{Thermochemistry of oxidized graphite upon thermal process}

3.1.1 Thermogravimetry (TG) and Differential Scanning Calorimetry (DSC) analysis. As mentioned above, the introduction of oxygen species during the electro-oxidation processing decreased the thermal stability of graphite material., TGA was used to monitor the differences of thermal stabilities between pristine graphite (PG) and electro-treated graphite (EGO). As shown in Fig. 1, the pristine graphite grinded from the simulative nuclear graphite matrix ball performed a high degree of thermal stability in insert atmosphere. The weight just dropped by $2.5 \%$, most likely due to moisture loss and detachment of adsorbed oxygen atoms. And there is almost no mass loss of the pristine graphite before $700{ }^{\circ} \mathrm{C}$ in air atmosphere, and the complete oxidization and decomposition of pristine graphite happened after $900{ }^{\circ} \mathrm{C}$ (Fig. 1a). By contrast, the electro-treated graphite sample behaved easily oxidative and decomposable. In Fig. 1b, there was a dramatic weight loss between $90{ }^{\circ} \mathrm{C}$ and $250{ }^{\circ} \mathrm{C}$ in insert atmosphere, and the ultimate weight loss was about $30 \%$ at $1000{ }^{\circ} \mathrm{C}$ compared with $2.5 \mathrm{wt} \%$ for the pristine graphite. In air atmosphere, the complete decomposition of EGO happened at $700{ }^{\circ} \mathrm{C}, 200{ }^{\circ} \mathrm{C}$ lower than the pristine graphite. It reveals that the electrooxidation effects significantly lowered the complete decomposition temperature of oxidized graphite compared with untreated pristine graphite.

Fig. 2a shows the detailed TGA results of EGO in insert atmosphere. The mass in percentage with increasing temperature is displayed on the left axis, along with the derivative mass percentage related to the temperature on the right axis. The EGO began to lose weight upon thermal treatment even below $100{ }^{\circ} \mathrm{C}$, which was associated with the escape of adsorbed water and gas molecules as stated earlier. With temperature rising, two main peaks and two small peaks in the derivative weight are observed near $91^{\circ} \mathrm{C}, 211^{\circ} \mathrm{C}, 383^{\circ} \mathrm{C}$ and $541^{\circ} \mathrm{C}$, which indicated that there were two large mass transitions and two minor mass fluctuations as EGO was heated. The peak near $91{ }^{\circ} \mathrm{C}$ is widely considered due to the loss of interstitial $\mathrm{H}_{2} \mathrm{O}$ in graphite lattice. At around $216{ }^{\circ} \mathrm{C}$, the weight loss rate of EGO reached a maximum. This may be due to the decomposition of oxygen functional groups in the EGO. The weight loss at around $383{ }^{\circ} \mathrm{C}$ originated from the pyrolysis of stubborn oxygen-containing species. The peak at $541{ }^{\circ} \mathrm{C}$ can be attributed to the sublimation of the carbon skeletons of EGO. ${ }^{11}$ The detailed causes of weight loss will be presented in the TGA-MS results in next section. In Fig. 2b, there is only one obvious peak in the derivative weight of PG at $204{ }^{\circ} \mathrm{C}$ during the thermal analysis. This weight transition can be attributed to the dissociation of absorbed oxygen atoms from the backbone of pristine graphite.

A typical DSC scan of EGO with the heating rate of $10{ }^{\circ} \mathrm{C} \mathrm{min}^{-1}$ performed at varying temperatures is shown in Fig. 2c. There was a dramatic weight loss at an onset temperature of approximately $106{ }^{\circ} \mathrm{C}$ accompanied by a stronglyexothermic DSC peak between $106{ }^{\circ} \mathrm{C}$ and $600{ }^{\circ} \mathrm{C}$. The features correspond to the transformation of thermolabile function groups and the formation of evolved gases.
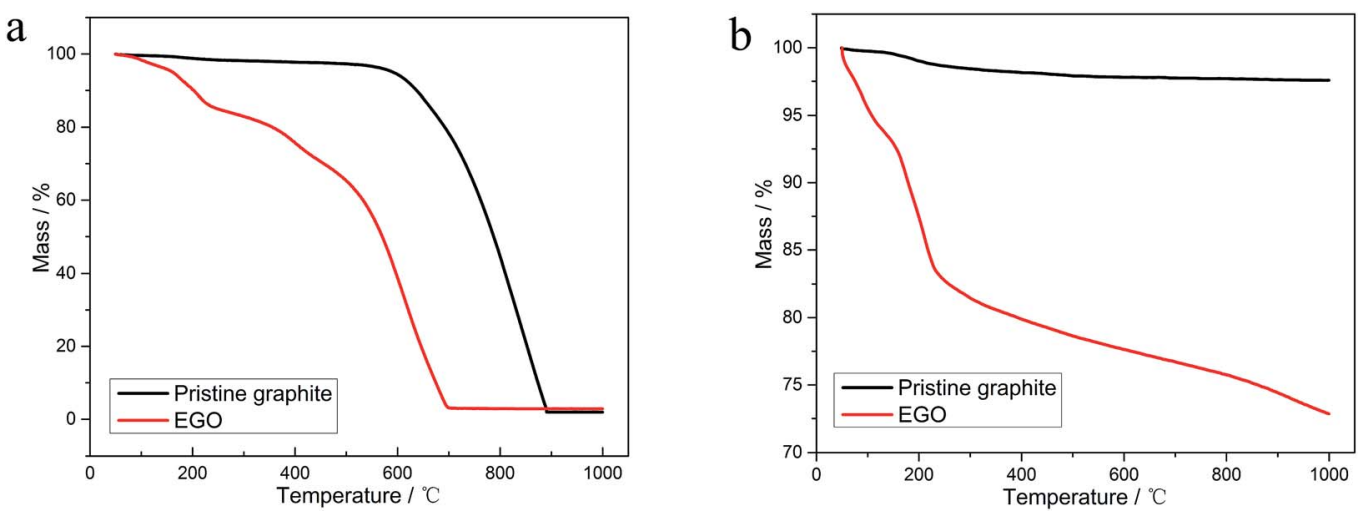

Fig. $1 \mathrm{TGA}$ thermograms with a heating rate of $10{ }^{\circ} \mathrm{C} \mathrm{min}^{-1}$ of (a) $\mathrm{EGO}$ thermal reduction compared with the pristine graphite oxidation in air atmosphere; (b) EGO thermal reduction compared with the pristine graphite oxidation in $\mathrm{N}_{2}$ atmosphere. 

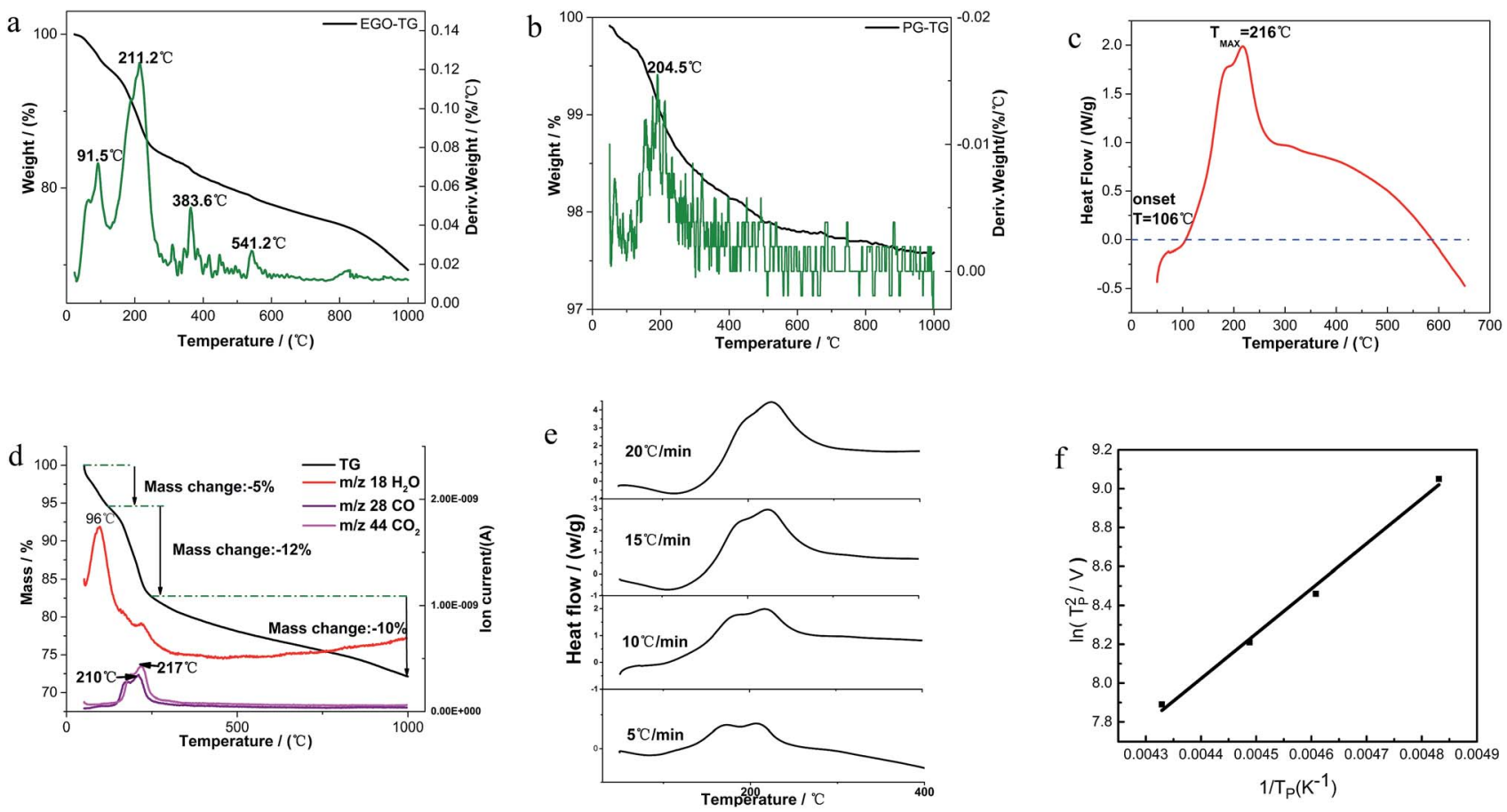

Fig. 2 (a) TGA thermograms with a heating rate of $10{ }^{\circ} \mathrm{C} \mathrm{min}^{-1}$ of derivative weight of EGO; (b) TGA thermograms with a heating rate of $10^{\circ} \mathrm{C} \mathrm{min}^{-1}$ of derivative weight of pristine graphite; (c) DSC thermogram of EGO in $100 \mathrm{~mL} \mathrm{~min}^{-1} \mathrm{~N}_{2}$ flow; heating rate $10^{\circ} \mathrm{C}$ min ${ }^{-1}$; (d) TGA-MS spectra of EGO with a heating rate of $10{ }^{\circ} \mathrm{C} \mathrm{min}^{-1}$ between $\mathrm{rt}$ and $1000{ }^{\circ} \mathrm{C}$; (e) dynamic mode DSC thermograms with systematic variation in heating rate; (f) $\ln \left(\frac{V}{T_{\mathrm{P}}^{2}}\right)$ are as a function of $1 / T_{\mathrm{P}}$.

3.1.2 Decomposition of EGO by TGA-MS analysis. To determine the content of the evolved gases that were generated from the thermal process, a TGA-MS experiment was performed where the outlet gas was analyzed by ion mass spectrometry. As shown in Fig. 2d, the main gas products of the decomposition reaction were found to be $\mathrm{CO}_{2}, \mathrm{CO}$ and $\mathrm{H}_{2} \mathrm{O}$ as expected. Between room temperature and $120{ }^{\circ} \mathrm{C}$, mainly water $(\mathrm{m} / \mathrm{z} 18,5 \%)$ was released, followed by a further weight loss of $12 \%$ that originated from $\mathrm{CO}_{2}, \mathrm{H}_{2} \mathrm{O}, \mathrm{CO}(\mathrm{m} / z 44$, $18,28)$ in the temperature range of $160{ }^{\circ} \mathrm{C}$ and $250{ }^{\circ} \mathrm{C}$. And then the carbonaceous species $\left(\mathrm{CO}_{2}, \mathrm{CO}\right)$ remained a lower light intensity level that was barely detectable after $260{ }^{\circ} \mathrm{C}$, which indicated that the decomposition of low stabilization oxygen moieties was mostly completed between $125{ }^{\circ} \mathrm{C}$ and $250{ }^{\circ} \mathrm{C}$. At the next stage of thermal process, the weight dropped steadily and nearly $10 \%$ mass lost. The causes could be attributed to the transformation of thermotolerant $\mathrm{O}$-species and the sublimation of the carbon framework. ${ }^{11,21}$

3.1.3 Results of the decomposition kinetics analysis. The DSC curve illustrates a wide exothermic peak of EGO upon heating at $10 \mathrm{~K} \mathrm{~min}^{-1}$ around $210^{\circ} \mathrm{C}$ in Fig. $2 \mathrm{e}$. The reaction was significant in the synchronization with the decomposition of oxygen-containing group. And the decomposition reaction activation energy could be estimated by applying Kissinger equation which described the relationship between heating rate and peak temperature ${ }^{9,16}$

$$
\ln \left(\frac{V}{T_{\mathrm{P}}^{2}}\right)=\ln \left(\frac{A R}{E_{\mathrm{a}}}\right)-\frac{E_{\mathrm{a}}}{R T_{\mathrm{P}}}
$$

where $V$ is heating rate, $T_{\mathrm{P}}$ is the temperature at which the heat flow reaches maximum, $E_{\mathrm{a}}$ is activation energy, $A$ is frequency factor and $R$ is universal gas constant. Plotting $\ln \left(\frac{V}{T_{\mathrm{P}}^{2}}\right)$ vs. $\frac{1}{T_{\mathrm{P}}}$ offers linear regression, from which activation energy $E_{\mathrm{a}}$ and frequency factor $A$ are calculated. In this research, four different heating rates $\left(5,10,15\right.$, and $\left.20{ }^{\circ} \mathrm{C} \mathrm{min}^{-1}\right)$ were adopted. The results of $\ln \left(\frac{V}{T_{\mathrm{P}}{ }^{2}}\right)$ vs. $\frac{1}{T_{\mathrm{P}}}$ are plotted in Fig. $2 \mathrm{f}$. The activation energy originated from these data was about $115.6 \mathrm{~kJ} \mathrm{~mol}^{-1}$ (1.20 eV per atom). The activation energy of electrochemical produced GO obtained in this work (115.6 $\mathrm{kJ} \mathrm{mol}^{-1}$ ) was lower than the GO reported previously using traditional synthetic methods. ${ }^{9,10,16}$

\subsection{Morphology and structural evolution of oxidized graphite during thermal annealing process in insert atmosphere}

The morphology of the thermal treated EGO was examined using a field-emission SEM equipment. For the parent EGO samples, high-resolution SEM images could be easily obtained without any pretreatments, suggesting that the products from the electro-treatment process had strong conductivity. This feature reveals that the pristine nuclear graphite was partially 
oxidized during the electrochemical process, which is also confirmed by XRD data (seen in Fig. 3e).

Some representative SEM images of the thermally-treated EGO at different temperatures and the results of nitrogen adsorption/desorption isothermal analysis are shown in ESI data. $\uparrow$ The morphology of REGO (Fig. S1 $\dagger$ ) tends to be more and more fluffy with the annealing temperature rising, besides the results of BET $\mathrm{N}_{2}$ surface area clearly confirmed that the porosity of REGO continues to increase along with the increasing of annealing temperature. The BET $\mathrm{N}_{2}$ surface area of the parent EGO is only $6.87 \mathrm{~m}^{2} \mathrm{~g}^{-1}$, while we obtain higher area values when the product had been thermal-treated. And the fastest surface area rising period happened between $150^{\circ} \mathrm{C}$ and $200{ }^{\circ} \mathrm{C}$, which is exactly the time of the occurrence of the decomposition of the main oxygen moieties. And ultimately the REGO presents a worm-like morphology in the low
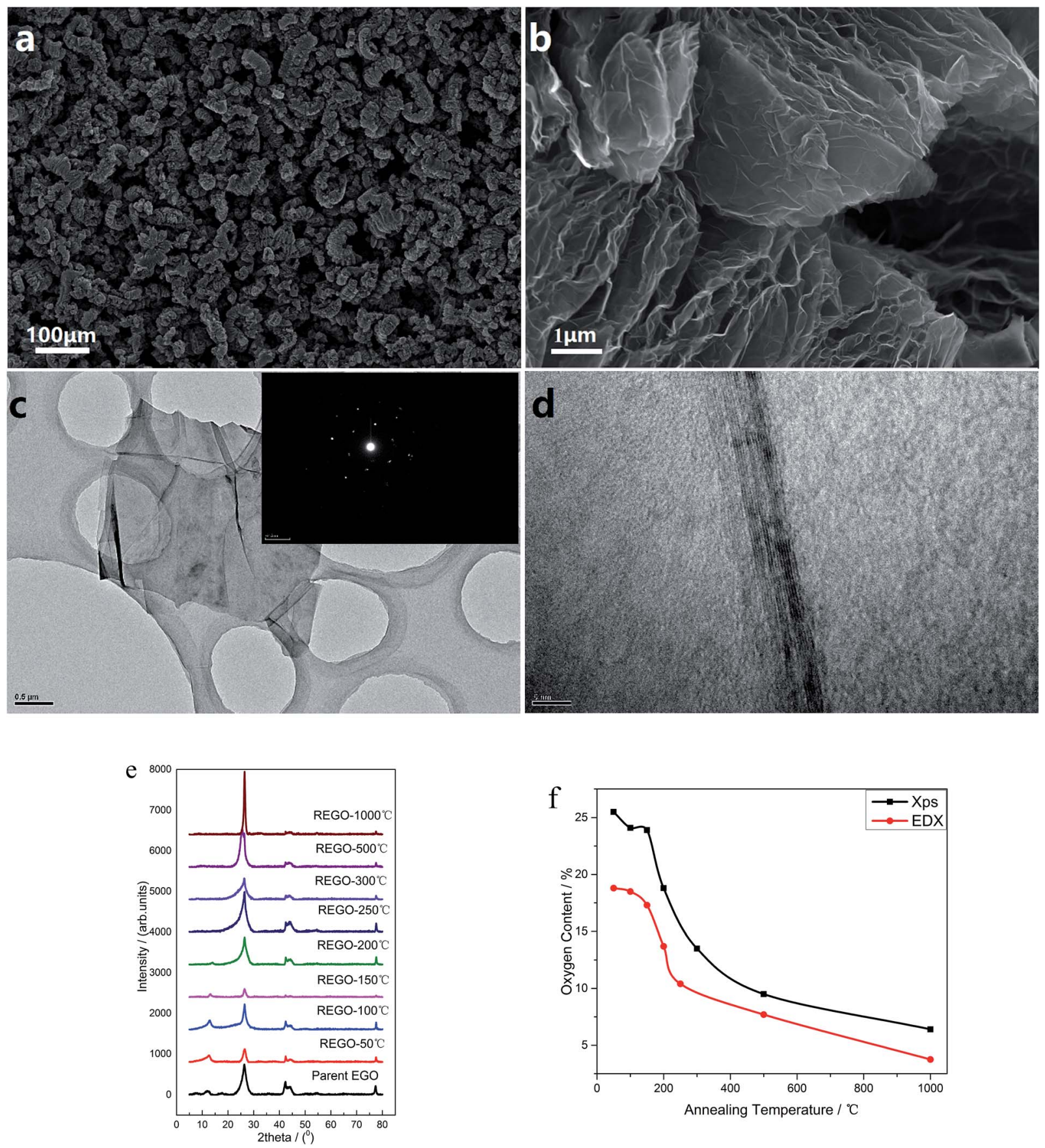

Fig. 3 (a) Morphology of REGO-1000 ${ }^{\circ} \mathrm{C}$ (at $100 \times$ magnification); (b). Morphology of REGO-1000 ${ }^{\circ} \mathrm{C}$ (at $10000 \times$ magnification); (c) lowmagnification TEM image of REGO-1000 ${ }^{\circ} \mathrm{C}$ and corresponding SAED patterns; (d) high-resolution TEM image of REGO-1000 ${ }^{\circ} \mathrm{C}$ (e) XRD spectra of REGO annealed at different temperature, compared with that of pristine graphite; (f) temperature-dependence of oxygen content of reduced product measured by XPS and EDX. 
magnification (Fig. 3a) and an accordion-like structure in the high magnification (Fig. 3b) when the annealing temperature reaches $1000{ }^{\circ} \mathrm{C}$. Meanwhile, the BET surface area of REGO$1000{ }^{\circ} \mathrm{C}$ increased to $45.7 \mathrm{~m}^{2} \mathrm{~g}^{-1}$. In addition, the elemental composition of thermally-reduced EGO at different temperatures was investigated by SEM-EDX. According the EDX data (Fig. 3f), O-content of thermally-reduced EGO were significantly diminished with annealing temperatures rising. Similar trends could be observed from the XPS data, although there were some numerical differences in the two observation results because of the different principles of observation method and instruments.

Fig. 3c depicts the transmission electron microscopy (TEM) and corresponding SAED characterization results of REGO annealed at $1000{ }^{\circ} \mathrm{C}$. Low-magnification TEM (Fig. 3c) observation indicates that the reduced products were inhomogeneous micrometer-sized flakes. And some sheet-like graphitic stackings and discontinued fringes with corrugated structure can be observed from the high-resolution TEM. The discontinued fringes in the HRTEM image (Fig. 3d) were attributed to the defective structures, and it indicates the interlayered coherence was destroyed. As the EGO was identified to be a heterogeneous and disordered system by previous research, ${ }^{5}$ the distorted structure of REGO could not be determined from the thermal reduction process or the prior electrolytic process. The typical well-defined diffraction spots in SAED pattern depicts that the amorphous state of the EGO was restored, confirming that the well-crystallized structure of REGO-1000 ${ }^{\circ} \mathrm{C}$ as XRD data had presented (see below). But the crystallinity was not as perfect as pristine graphite, because of the defects from the thermal-reduction process of O-moieties that still remained on the graphitic structure.

The reduction and crystalline degree of thermally-treated oxidized graphite were further characterized by X-ray diffraction (XRD). As validated by the XRD spectra, the starting pure nuclear graphite before thermal treatment exhibited a characteristic peak (002) located at around $26.4^{\circ}$ (seen in ESI, Fig. S2a $\dagger$ ). The parent EGO exhibits a main peak at $26.51^{\circ}$, and another smaller peak (001) can be observed at $12.52^{\circ}$ associated with the oxide phase of EGO caused by electro-oxidation treatment (Fig. S2b $\dagger$ ). The XRD patterns of the samples of EGO heated at different temperatures are shown in Fig. 3e. After thermal treatment, the peak at $12.52^{\circ}$ becomes smaller and smaller with the temperature rising and completely disappears when the temperature rises to $250{ }^{\circ} \mathrm{C}$. Meanwhile, the peak around $26^{\circ}$ becomes sharper and continuously shifts to the right with temperature rising. The REGO sample at $1000{ }^{\circ} \mathrm{C}$ exhibited a structure closer to the pristine nuclear graphite as showed by the shifting of (002) peak back to $26.4^{\circ}$. However, its FWHM still remained larger than that of pristine graphite, which suggested the presence of strains or defects. Overall, the results of XRD indicate that oxygen species on the oxidized

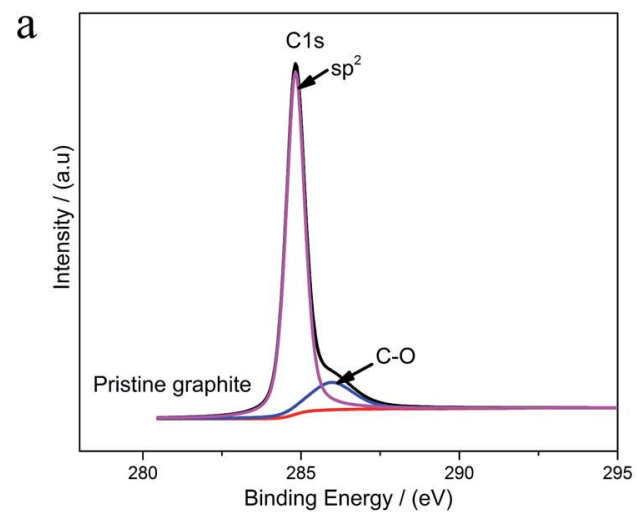

b
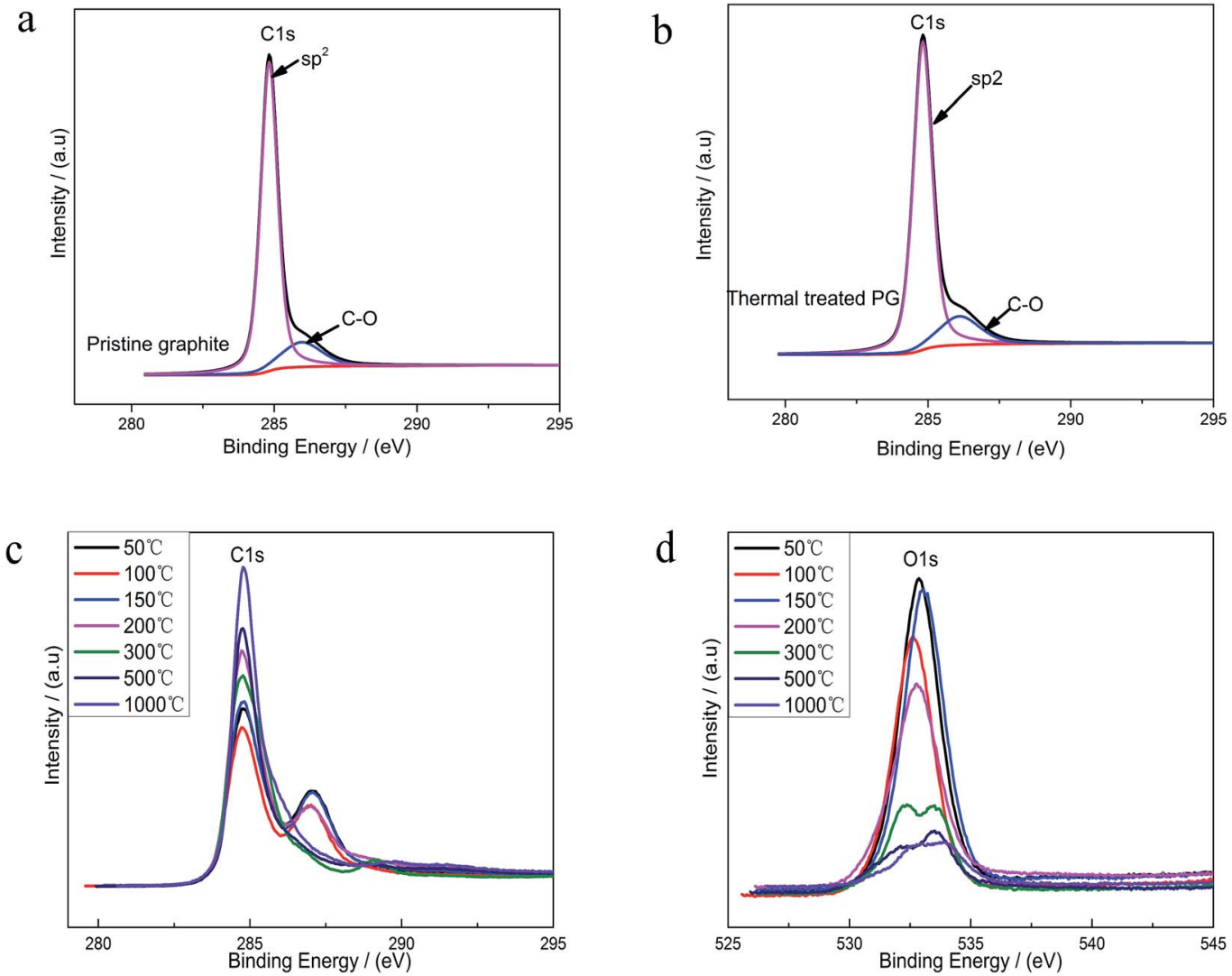

Fig. 4 (a) C 1s XPS spectra for pristine graphite (PG); (b) O 1s XPS spectra for PG; (c) C 1s spectra measured on EGO after annealing at increasing temperatures; (d) $O$ 1s spectra measured on EGO after annealing at increasing temperatures. 
graphite was mostly removed during the thermal annealing process and the amorphous phase of oxidized graphite was largely transformed into crystalline phase.

XPS was used to analyze the changes of the structure and the surface chemical composition of EGO during the thermal process. The C 1s spectra of pristine graphite (PG) (Fig. 4a) before electro-treatment shows two peaks, which were related to $\mathrm{sp}^{2}$-hybridized $(284.5 \mathrm{eV})$ and hydroxyl configurations $(285.6 \mathrm{eV})$ respectively. This significant $\mathrm{C}-\mathrm{O}$ peak (around $285.6 \mathrm{eV}$ ) in pristine graphite was associated with atmospheric oxidation during the manufacturing processes, which had previously been reported. ${ }^{22-24}$ The XPS spectra of the PG sample after high temperature $\left(1000{ }^{\circ} \mathrm{C}\right)$ processing in inert atmosphere (Fig. 4b) exhibit a similar graphical shape as the untreated one (Fig. 4a), and the intensity of $\mathrm{C}-\mathrm{O}$ single bond had not lessened. Consequently, this phenomenon suggests that the inherent $\mathrm{C}-\mathrm{O}$ of PG was super-stable and hard-to-remove during heat treatment process. At the same time, we found four different bond types accounting for the $\mathrm{C}$ 1s spectra of parent EGO. In accordance with the results of prior literature, the XPS C 1s spectrum of the parent EGO was deconvoluted into four peaks: the first peak occurring at $284.6 \mathrm{eV}$ could be assigned to be $\mathrm{sp}^{2}$-hybridized carbons; the second peak at $285.4 \mathrm{eV}$ was assigned to $\mathrm{C}-\mathrm{O}$ or $\mathrm{C}-\mathrm{O}-\mathrm{C}$ (hydroxyl or epoxide) groups; and the peak at $287.1 \mathrm{eV}$ for the $-\mathrm{C}=\mathrm{O}$ (carbonyl) bond types, and $288.1 \mathrm{eV}$ for $\mathrm{HO}-\mathrm{C}=\mathrm{O}$ (carboxylic) bond types. ${ }^{5,25}$ Referring to the previous researches of graphite oxide, epoxide and hydroxyl were considered to be highly likely distributed on the basal planes of EGO's skeleton, while carbonyl and carboxyl were located at the edges of oxidized graphite. ${ }^{26-29}$ Noting that except $\mathrm{sp}^{2}$ fraction, $>\mathrm{C}=\mathrm{O}$ groups was the maximum contribution of $\mathrm{C} 1 \mathrm{~s}$, which was more than the two other bond types $\mathrm{C}-\mathrm{O}$ (hydroxyl or epoxide) and $\mathrm{O}-\mathrm{C}=\mathrm{O}$ (carboxylic). Additionally, the total $\mathrm{C}=\mathrm{O}$ double bonded contribution (including $>\mathrm{C}=\mathrm{O}$ and $\mathrm{COOH}$ groups) was more than $\mathrm{C}-\mathrm{O}$ single bonded groups. ([ $>\mathrm{C}=\mathrm{O}+\mathrm{COOH}] /[\mathrm{C}-\mathrm{OH}$ $+\mathrm{C}-\mathrm{O}-\mathrm{C}]=1.7)$. This can be interpreted that the $\mathrm{C}-\mathrm{O}$ single bonded groups tended to be oxidized to become $\mathrm{C}=\mathrm{O}$ double bonded species at harsh electro-oxidization conditions. ${ }^{5}$

Upon thermal treatment, the $\mathrm{C} 1 \mathrm{~s}$ spectrum of EGO presented a transformation from a double peak to a single sharp peak with annealing temperature rising (Fig. 4c). The evolution of the $\mathrm{C} 1 \mathrm{~s}$ spectrum reveals an increase of C-content with annealing temperature rising, and a corresponding decrease of the O-species. 96\% C-content of REGO could be achieved with a

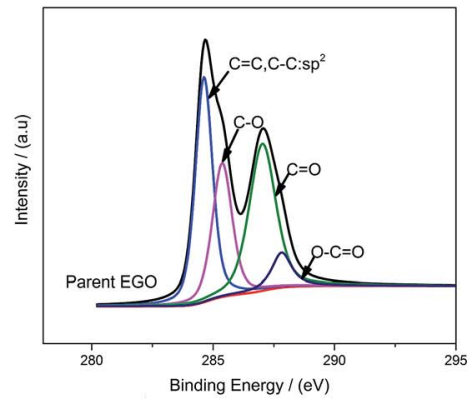

d

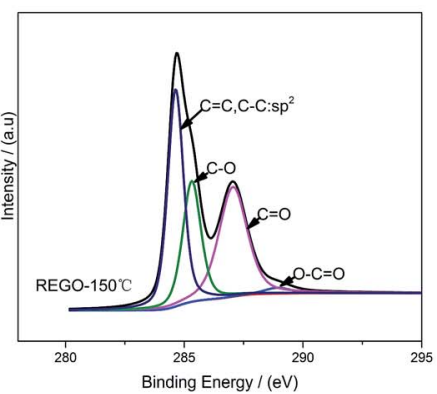

b

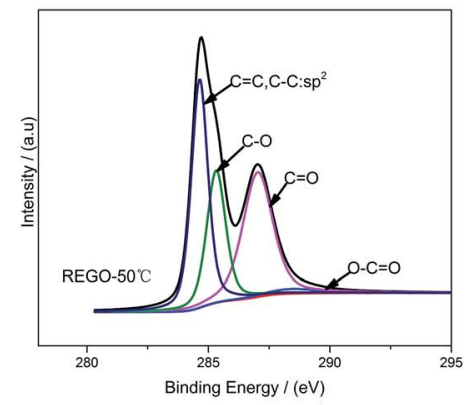

e

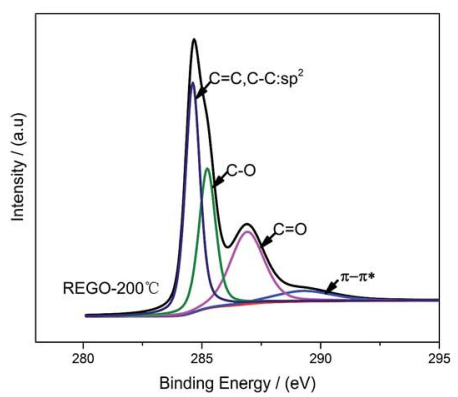

c

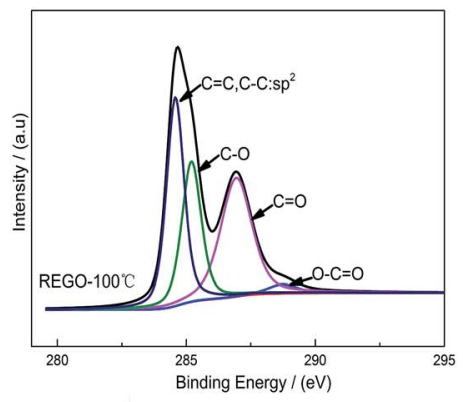

f

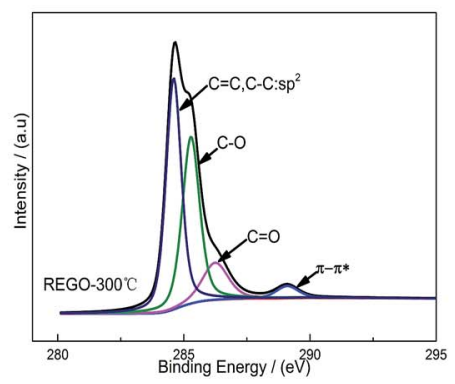

g

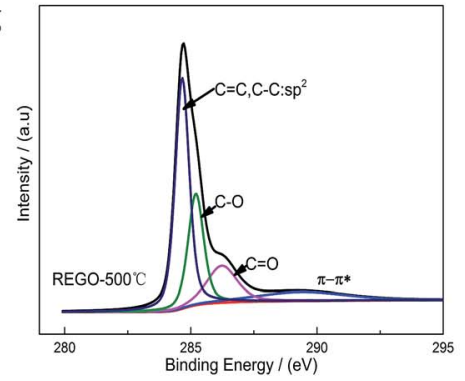

$\mathrm{h}$

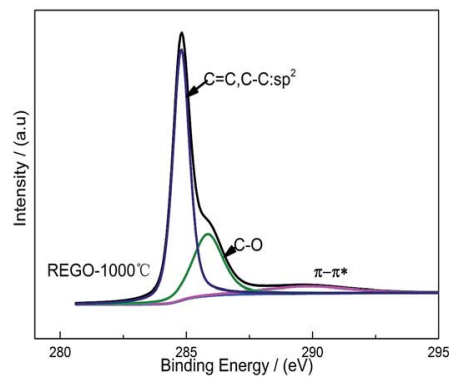

Fig. 5 C 1s XPS spectra deconvoluted peaks with increasing annealing temperature. 
temperature reaching $1000{ }^{\circ} \mathrm{C}$, with only about $4 \% \mathrm{O}$ contribution remained.

The C 1s XPS spectra of REGO annealed at different temperatures are illustrated in Fig. 5, and the changes of relative contribution of the bond types with increasing temperature are presented in Fig. 7a. Between $50{ }^{\circ} \mathrm{C}$ and $150{ }^{\circ} \mathrm{C}$, the relative intensities of the four bond types undulate slightly and almost maintains a certain level. From $150{ }^{\circ} \mathrm{C}$ to $200{ }^{\circ} \mathrm{C}$, the edge-plane $\mathrm{HO}-\mathrm{C}=\mathrm{O}$ suffers a sharp decline and becomes extinct at $200^{\circ} \mathrm{C}$ accompanied with a slight rise of $\mathrm{C}-\mathrm{O}$ bond types. And a $\pi-\pi^{*}$ shakeup satellite peak at around $290 \mathrm{eV}$ appears at the same time, which indicates that the delocalized $\pi$ conjugation of aromatic carbon structure on REGO was on some level restored. ${ }^{25}$ Then, the $\mathrm{C}-\mathrm{O}$ shows a slight increase from $200{ }^{\circ} \mathrm{C}$ to $300{ }^{\circ} \mathrm{C}$ and subsequently diminishes between $300{ }^{\circ} \mathrm{C}$ and $500{ }^{\circ} \mathrm{C}$. And the upward trend of $\mathrm{C}-\mathrm{O}$ in the range of $200{ }^{\circ} \mathrm{C}$ to $300{ }^{\circ} \mathrm{C}$ has also been reported in previous researches..$^{25,30,31}$ The rise of $\mathrm{C}-\mathrm{O}$ at initial stage was interpreted to be contributed by newly-formed phenolic group. And these phenolic groups were distributed between graphite sheets and intercalated into the interlayer galleries between intact conjugated domains. Due to its special intercalating position, the completely thermal decomposition of such $\mathrm{C}-\mathrm{O}$ is thermodynamically difficult. ${ }^{25,31}$ And the transformation of $\mathrm{O}$ 1s spectrum provides further robust evidence on the generation of phenolic groups (later in the paper). The subsequent relative decline of $\mathrm{C}-\mathrm{O}$ between $300{ }^{\circ} \mathrm{C}$ and $500{ }^{\circ} \mathrm{C}$ could be attributed to the elimination of $\mathrm{C}-$ $\mathrm{OH}$ which distribute at the edge of graphite sheets. Meanwhile, the $>\mathrm{C}=\mathrm{O}$ started a continued decline from $150{ }^{\circ} \mathrm{C}$, and ultimately disappeared at the temperature of $1000{ }^{\circ} \mathrm{C}$.

The internal conversion of $\mathrm{C}=\mathrm{O}$ to $\mathrm{C}-\mathrm{O}$ at low reduction temperature was considered to be the reason of the initial increase of $\mathrm{C}-\mathrm{O}$ single bond. ${ }^{25}$ The dispersion of the peak positions as a function of annealing temperature is shown in Fig. 7b. In general, all the peaks fluctuate within a fixed range. Notable among them is that the $>\mathrm{C}=\mathrm{O}$ peak turned to shift to lower binding energy side representative of $\mathrm{C}-\mathrm{O}$ single bond between $200{ }^{\circ} \mathrm{C}$ to $300{ }^{\circ} \mathrm{C}$, which indirectly reconfirmed the transformation of $>\mathrm{C}=\mathrm{O}$ to $\mathrm{C}-\mathrm{O}$.

As shown in Fig. 6, the O 1s spectra of parent EGO can be deconvoluted into three main peaks: the first peak at $531.4 \mathrm{eV}$ is assigned to $\mathrm{C}=\mathrm{O}$ ( $\mathrm{O}$ atom doubly bonded to aromatic carbon a

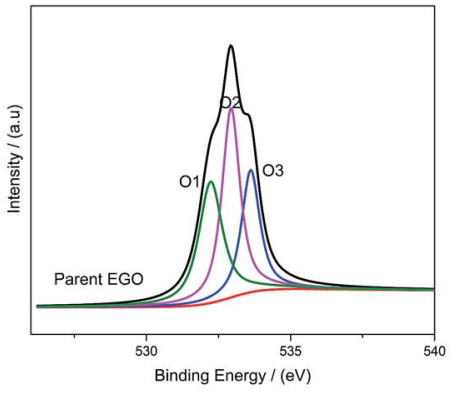

$\mathrm{d}$

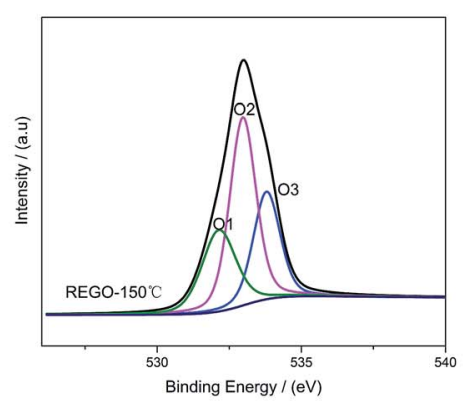

b

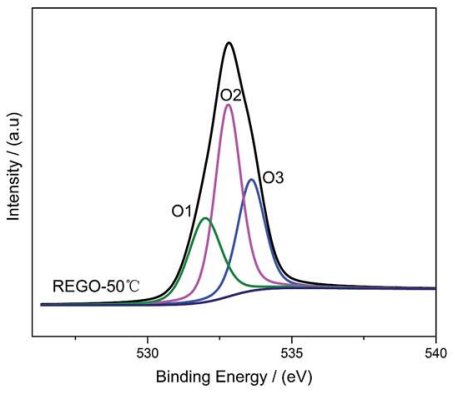

e

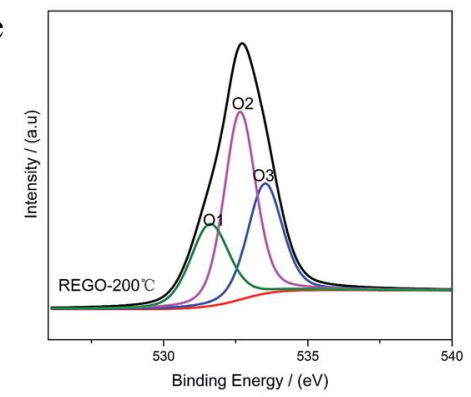

c

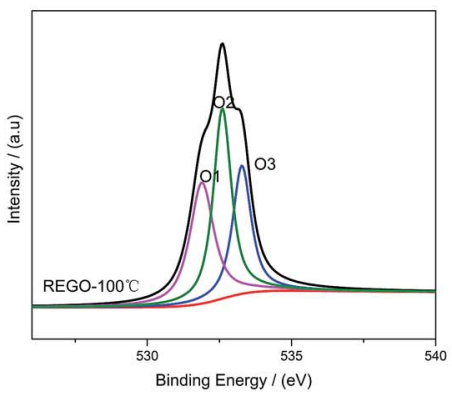

f

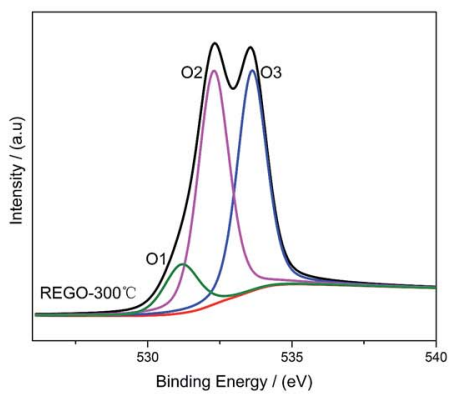

g

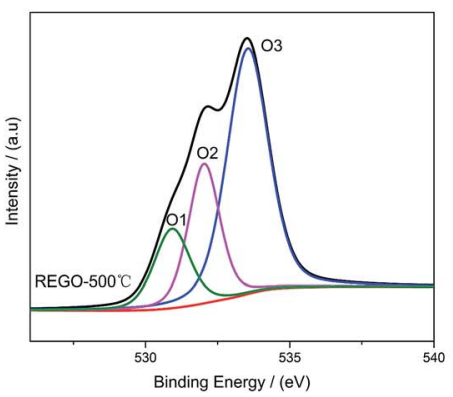

$\mathrm{h}$

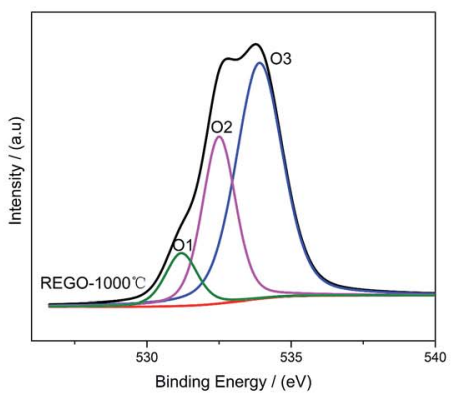

Fig. 6 1s XPS spectra deconvoluted peaks with increasing annealing temperature. 
labelled as $\mathrm{O} 1)$, the second peak $(532.6 \mathrm{eV})$ is assigned to $\mathrm{C}-\mathrm{O}(\mathrm{O}$ atom singly bonded to aliphatic carbon labeled as $\mathrm{O} 2$ ), and the third peak $(533.5 \mathrm{eV})$ can be due to the presence of phenolic group (O atom singly bonded to aromatic carbon labeled as O3). ${ }^{25,32-35}$ These assignments are consistent with the previous researches, indicating that our results are reliable. Thermal reduction of EGO creates a shift of $\mathrm{O}$ 1s spectra from low energy side to the high, and from a single peak to a double feature with the rise of temperature (Fig. $4 \mathrm{~d}$ ). From $50{ }^{\circ} \mathrm{C}$ to $150{ }^{\circ} \mathrm{C}$, both the relative intensity and integrated intensity show no obvious changes (Fig. 7c). The integrated intensity of oxygen moieties started to decrease since the temperature reached $200{ }^{\circ} \mathrm{C}$, and simultaneously the relative intensity of $\mathrm{O} 3$ increased rapidly with the decrease of $\mathrm{O} 1$ and $\mathrm{O} 2$ between $200{ }^{\circ} \mathrm{C}$ and $500^{\circ} \mathrm{C}$. In the following, the intensity of O-moieties (both the relative intensity and integrated intensity) changed marginally from $500{ }^{\circ} \mathrm{C}$ to $1000{ }^{\circ} \mathrm{C}$.

In summary, the peak of the graphitic carbon $\mathrm{sp}^{2}$ component became largely dominant with the annealing temperature rising, along with the removal of main oxygen groups (including $\mathrm{C}-\mathrm{O}-\mathrm{C},>\mathrm{C}=\mathrm{O}$ and $\mathrm{HO}-\mathrm{C}=\mathrm{O}$ ). However, the $\mathrm{C} 1 \mathrm{~s}$ XPS spectrum of REGO- $1000{ }^{\circ} \mathrm{C}$ still exhibits oxygen-containing groups. The nature of this persistent residual oxygen that last remains in REGO was confirmed to be $\mathrm{C}-\mathrm{O}$ bond types by XPS spectra (Fig. 5h). During the overall process, the relative intensity of O3
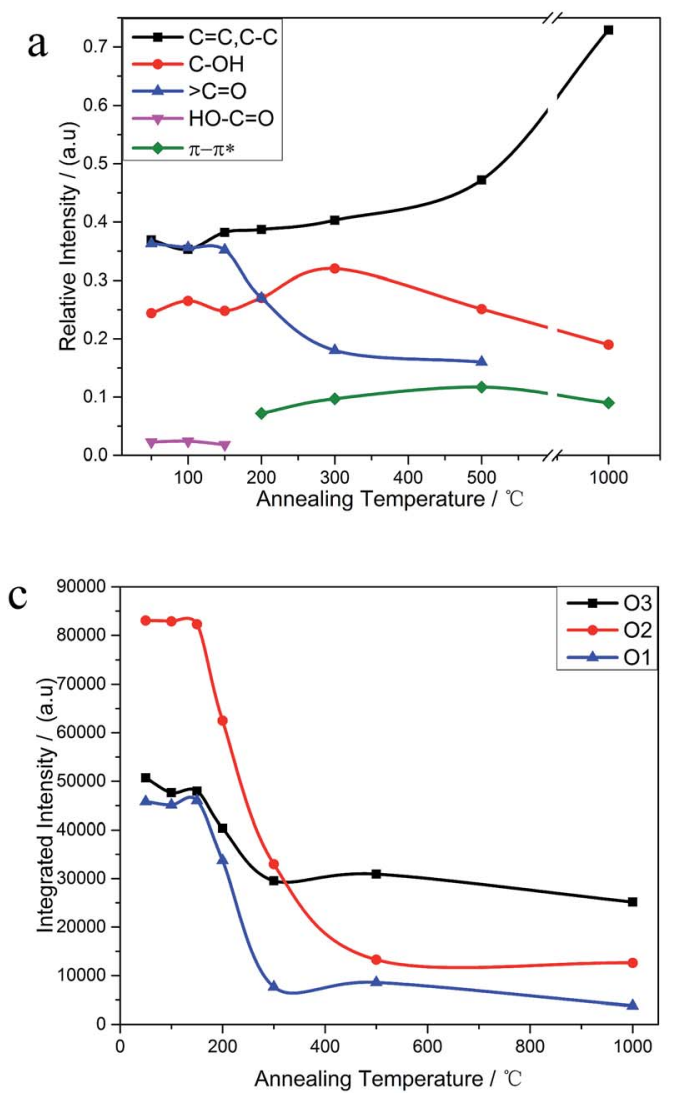

(phenol group) sustained a general upward trend although the integrated intensity of all O-moieties decreased. Hence, it can be envisaged that the increase of relative intensity of C-O in $\mathrm{C} 1 \mathrm{~s}$ peak was mainly contributed by newly-formed phenolic groups. Furthermore, the $\mathrm{C}-\mathrm{O}$ staying in the REGO structure was confirmed to be extremely similar to that observed in the pristine graphite material according to their peak positions. Meanwhile, the intensities of remaining $\mathrm{C}-\mathrm{O}$ were much smaller than those in parent EGO but a little more than those in pristine graphite. These features suggest that the thermallystable O-species residues in the REGO might partly come from the built-in oxygen moieties of pristine graphite, and the rest thermally-stable $\mathrm{C}-\mathrm{O}$ single bond was generated during the heat treatment process.

\subsection{Discussion of results}

3.3.1 Analysis of thermal process. To investigate the thermal reduction mechanism of oxidized graphite from the electro-oxidation process of nuclear graphite matrix, several experiments have been carried out to monitor the process of pyrolysis of EGO as presented before. The TGA, DSC, TGA-MS and XPS data provide detailed information on the thermal annealing process of EGO.

On the basis of the above results, four stages can be proposed to describe the continuous thermal reduction process b
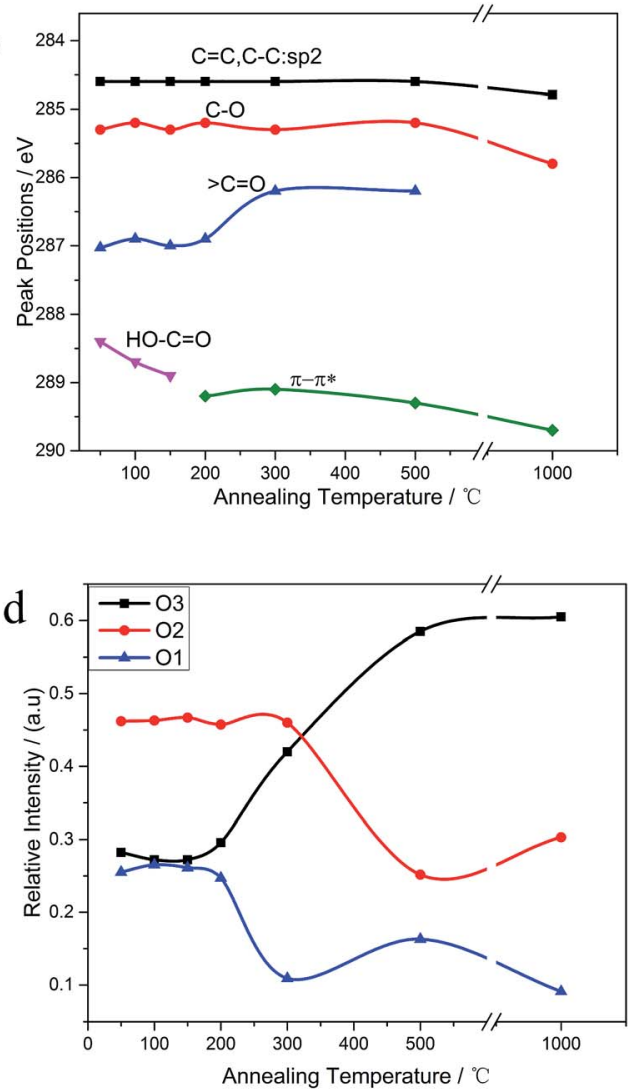

Fig. 7 (a) The relative contribution of $C$ 1s peak components estimated by dividing the area under each component; (b) temperature-dependence of the peak-position of $\mathrm{C}$ 1s peak components; (c) temperature-dependence of the integrated intensity of $\mathrm{O} 1 \mathrm{~s}$ peak components; (d) the corresponding relative contribution estimated by dividing the area under each component by whole $\mathrm{O}$ 1s peak-area. 
of EGO: (1) the dehydration stage, in which water intercalated or absorbed in the EGO sheets is volatilized between $30{ }^{\circ} \mathrm{C}$ and $120{ }^{\circ} \mathrm{C}$, while the carbon framework of EGO remains thermally stable; $^{21}(2)$ the stable stage, in which most of the O-species remain thermally stable in the temperature range of 120$160{ }^{\circ} \mathrm{C}$, and there are no obvious physical and chemical changes during this period; (3) the formal reduction stage, in which the conjugated structure is restored due to the decomposition of the carboxyl and carbonyl groups in the temperature region $160-250{ }^{\circ} \mathrm{C}$, and leading to the release of carbon oxide gases and the crystallization of oxidized graphitic structure accompanied with an exothermic process. Additionally, thermally superstable $\mathrm{C}-\mathrm{O}$ single bonded in the phenolic form is generated from the internal conversion of $\mathrm{C}=\mathrm{O}$ double bonded. In the meantime, complex carbon fragments, such as aliphatic, aromatic hydrocarbons and even some other carcinogenic organic compounds, are very likely released from the EGO during thermal degasification process as the prior literatures described; ${ }^{11,36,37}$ and (4) the rearrangement of carbon framework period, in which the remnant stubborn O-containing group involve in rearrangement or disproportionation reaction, and the sublimation of the carbon framework occurs simultaneously. At this period, the temperature generally remains above $260{ }^{\circ} \mathrm{C}$. More complex inorganic molecules are generated, and permanent defects of carbon skeleton are created that include missing carbon atoms or stable O-containing species. ${ }^{38-41}$ A schematic illustration of the temperature evolution of EGO is shown in Fig. 8 in accordance with the results we described above.

3.3.2 Influences of process parameters on the EGO reduction. From our experiment results, it is demonstrated that temperature is an important factor for the reduction process of EGO. It is generally accepted that the rise of temperature improves the efficiency of reduction considerably. It is inadequate to remove the oxygen species when the annealing temperature $\left(<160{ }^{\circ} \mathrm{C}\right)$ is too low. At higher temperatures $\left(>160{ }^{\circ} \mathrm{C}\right)$, easily decomposable oxygen species (ig. ${ }^{\succ} \mathrm{C}=\mathrm{O}$, $\mathrm{COOH})$ will resolve. While under extreme heat, permanent defects are generated that include missing carbon atoms or stable oxygen-containing structures. ${ }^{39,42}$ Meanwhile, the generated carbon oxides and water vapor may react with the carbon atoms at high temperature, which causes more defects (vacancies) than the case at low temperature., ${ }^{\mathbf{9} 10}$

Apart from temperature, heating rate is regarded as another key factor in thermal reducing oxidized graphite. At low external heating rates, graphite oxide undergoes a smooth, nonexplosive decomposition and yields products with low surface area and low degrees of exfoliation. Above a critical heating rate, the decomposition switches to the explosive mode and produces much higher internal porosity and larger surface area. So, it is significant to select a modest heat rate and annealing temperature. ${ }^{\mathbf{9 , 1 0 , 4 3}}$

Fundamentally, the very nature of EGO primarily determines the internal disciplines of reduction. The activation energy of deoxygenation of EGO in our experiment is lower than that of GO prepared by traditional methods. This phenomenon is intimately linked to the degree of oxidation of graphite material and the relative content of oxygen functionalities. EGO exhibits a thermolabile behavior that is because thermally-unstable $\mathrm{C}=\mathrm{O}$ bond types are dominant among the oxygen functionalities of EGO. Thus, the minimum energy required to start the deoxygenation reaction is relatively small.

3.3.3 Reduction mechanism of oxygen moieties and pathway of gas formation. It is clearly illustrated that the thermal reduction of EGO causes the evolvement of $\mathrm{CO}$ and $\mathrm{CO}_{2}$ gases by the TGA-MS experiment. And reportedly, the process of generation of $\mathrm{CO}$ and $\mathrm{CO}_{2}$ is widely considered to be a typical case of the pyrolysis of carboxyl and carbonyl groups. And the gas-evolved process is most likely to be triggered within highlyoxidized regions of EGO. Combining our TGA-MS and XPS results, it can be found that the emission of $\mathrm{CO}$ and $\mathrm{CO}_{2}$ and decomposition of carboxylic and carbonyl groups happened at the same temperature region $\left(160-250{ }^{\circ} \mathrm{C}\right)$. This has well confirmed that most of the carbonous low-molecular-weight gases are mainly derived from the thermal cracking of carboxyl and carbonyl species.

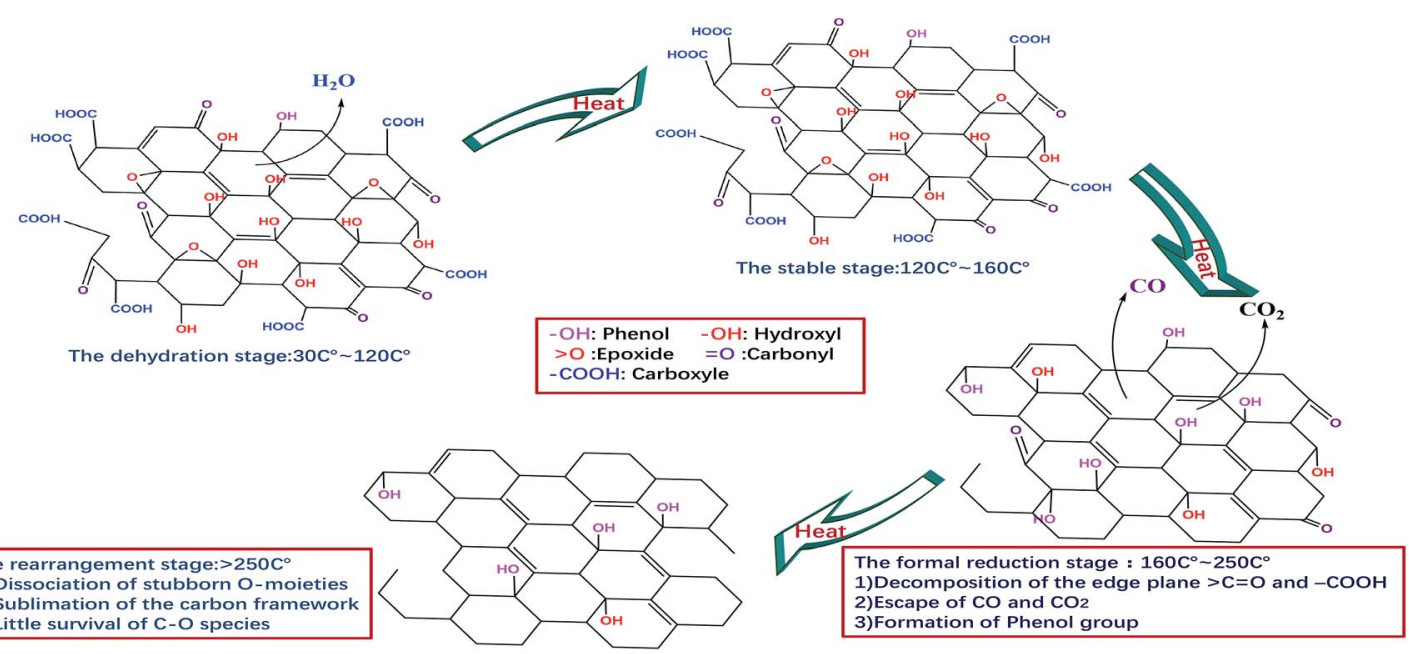

Fig. 8 Schematic diagram of the temperature evolution of EGO. 
The thermal deoxygenation of oxidized graphite is analogous to the 'elimination reaction' in organic chemistry, in which the small molecules are detached from the parent macromolecular. And the mechanisms of thermal decarbonylation and decarboxylation have been investigated by several research groups. ${ }^{40}$ Based on the previous researches' experience, the process of detachment of $\mathrm{CO}$ from $\mathrm{C}=\mathrm{O}$ in aldehyde form can be described as follow:

$$
\mathrm{H}_{\mathrm{H}}^{\mathrm{R}}>\mathrm{C}=\mathrm{O} \longrightarrow \mathrm{H}_{\mathrm{H}}^{\mathrm{R}}+\mathrm{C}=\mathrm{O}
$$

where $R$ is an aliphatic or aromatic radical. The reaction involves in a hydrogenation process: $\mathrm{H}$ atom transfers to the radical $R$, and simultaneously with the rupture of the $\mathrm{C}-\mathrm{C}$ bond; and the carbonyl functionalities are apparently degraded into hydrogen radical and $\mathrm{CO}^{\mathbf{1 4 , 1 5}}$

The elimination of $\mathrm{CO}_{2}$ from the carboxyl group can also follow the same route: ${ }^{40}$<smiles>[R]C(=O)OCC=O</smiles>

As described above, the $\mathrm{H}$ atom of the carboxyl group is attached to the nearest carbon atom of the radical $R$, with the separation of $\mathrm{CO}_{2}$ from the main parent carbon framework.

The removal of the carbon dioxide molecule from $\mathrm{COOH}$ group requires little energy, as the carboxylic compounds cannot take a coplanar geometry with the graphite sheet. That makes the carboxylic group become the most susceptible to thermal treatment. In certain situations, CO also can be detached due to the rupture of $\mathrm{C}-\mathrm{O}$ of carboxyl group:<smiles>[R][CH]O[CH]OC([R])=C=O</smiles>

The cleavage of $\mathrm{C}-\mathrm{O}$ makes the whole $-\mathrm{OH}$ transfer to the closest $\mathrm{C}$ atom of radical $R$ with the separation of $\mathrm{CO}$ molecule from the parent groups. Consequently, the carboxylic was actually converted into hydroxyl functionality. This conversion of carboxylic to hydroxyl can be regarded as one of origins of the rise of $\mathrm{C}-\mathrm{O}$ bond types between $200{ }^{\circ} \mathrm{C}$ and $300{ }^{\circ} \mathrm{C}$. And, the $\mathrm{C}-$ $\mathrm{OH}$ functional groups can also be transformed from $\mathrm{C}-\mathrm{O}-\mathrm{C}$ groups. The existed $\mathrm{C}-\mathrm{H}$ species in oxidized graphite transfer the $\mathrm{H}$ atom to the closest $\mathrm{O}$ atom of epoxy group and prompt the rupture of $\mathrm{C}-\mathrm{O}$, leading to the transformation of epoxy to hydroxyl. Besides, $\mathrm{C}-\mathrm{H}$ interacts with the adjacent hydroxyl group via atom migration, eliciting the dehydration reaction. ${ }^{\mathbf{4 0}}$

In addition, a high-temperature thermal annealing can directly eliminate $\mathrm{CO}$ from $\mathrm{C}=\mathrm{O}$ in ketone form through a onestep deoxygenation step: ${ }^{42}$

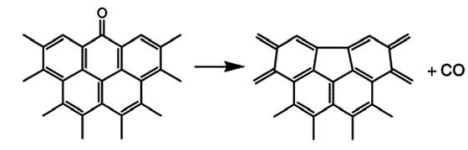

The dissociation of terminal carbonyl, carboxyl, and hydroxyl groups is feasible at low temperature $\left(160-250{ }^{\circ} \mathrm{C}\right)$. However, the removal of basal plane groups requires more energy, and can only be achieved at high temperature. And simultaneously more defects will be induced into the carbon backbone of REGO.

For example, the basal plane hydroxyl can be thermally reduced in two steps process and yields a monoxide (CO) with a defective graphite sheet: ${ }^{\mathbf{4 2}}$

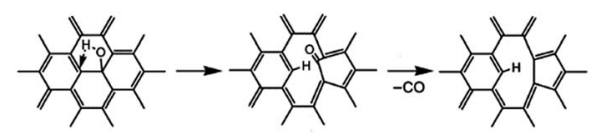

Interestingly, some research reported that hydroxyls linked to the inner aromatic domains of oxidized graphite can be expected to migrate to the edges of graphite sheets under the heat treatment and ultimately reduced at the edges domains. ${ }^{42}$

However, our XPS analysis illustrates the $\mathrm{OH}$-moieties on basal plane that was identified as phenolic group were the most thermally stable species in our work. The temperature of $1000{ }^{\circ} \mathrm{C}$ is inadequate to remove all the $\mathrm{C}-\mathrm{O}$ of the EGO. This indicates that there are high requirements for temperature to migrate and dissociate the basal plane $\mathrm{C}-\mathrm{O}$.

Nevertheless, the carbon framework becomes unstable and degrades at elevated temperatures. ${ }^{39}$ Meanwhile, other complex functionalities such as lactones, semiquinones, and ethers are manufactured with the evolution of volatile organic molecules. $^{31,40}$ The separation of parent EGO molecules, which requires the presence of unsaturated $\mathrm{C}-\mathrm{C}$ bonds involves a more complex series of reactions, and consequently causes vacancies and topological defects on the carbon backbone that have been thoroughly reported in the literatures. ${ }^{\mathbf{4 0 - 4 2}}$

The above mechanism we proposed match well with our experimental data, and can preliminarily explain the evolution of structure of oxidized graphite and the observed emission of $\mathrm{CO}_{2}$ and $\mathrm{CO}$ during thermal process. However, the deep mechanisms of these reactions are muddled and need further exploration.

\section{Conclusions}

In conclusion, thermochemistry of annealing process of oxidized graphite and the evolution of electronic structure of EGO during thermal process is systematically researched. Using these results, we have clarified some important issues concerning the deoxygenation of EGO upon the thermal treatment.

From the results above, it is apparent that the oxygencontaining functional groups of EGO are sensitive to thermal treatment. They will decompose upon heating and generate gases including $\mathrm{H}_{2} \mathrm{O}, \mathrm{CO}_{2}$, and $\mathrm{CO}$. Among these functionalities, the edge-plane $\mathrm{COOH}$ group is the most unstable one, and becomes the first to be removed. Additionally, the $\mathrm{C}=\mathrm{O}$ bond types decomposes with the annealing temperature rising, and thoroughly disappear at $1000{ }^{\circ} \mathrm{C}$. As the heat-sensitive $\mathrm{C}=\mathrm{O}$ and $\mathrm{COOH}$ groups are dominant among the O-moieties of EGO, most of the oxygen species can be removed at a temperature lower than $300{ }^{\circ} \mathrm{C}$. 
However, there is a significant amount of oxygen species persists in the reduced products, and they can't be removed even at high temperatures. The thermoresistant groups that residue in the structure of reduced EGO is identified to be $\mathrm{C}-\mathrm{OH}$ group. These types of species can be assured from two sources: the original $\mathrm{O}$-species of pristine nuclear graphite, and the newly-formed $\mathrm{C}-\mathrm{O}$ moieties in phenolic form during thermal annealing process. The good news is that the remnant oxygen species are stable enough to resist the effect of high-heat environment. Thus, it seems to be unnecessary to entirely eliminate these stubborn species as it can meet the requirements for further safety storage.

In addition, we synthetically analyze the continuous thermal process of EGO, and then expound the influence of temperature and heating rate on the reduction process, and lastly a plausible reduction mechanism has been discussed based on our detailed experimental data and the results from previous researches. However, the graphitic materials we used in these experiments hadn't been irradiated in the nuclear reactor. The chemical and physical properties of these materials are different from the irradiated graphitic material that generated from the decommissioning process of the HTGR. Thus, these results can only be essential references for optimizing the conditions for the largescale reduction of the EGO. Because such reduced products from nuclear industry must be stored or processed discreetly under ambient conditions or even in extreme environments, the influences of irradiation effect on the carbon framework of nuclear graphitic material is highly important for the applications of thermal processing method and should be considered in future researches.

\section{Conflicts of interest}

There are no conflicts to declare.

\section{Acknowledgements}

Support from the National Science and Technology Major Project (2014ZX06901-016) and Program for Changjiang Scholars and Innovative Research Team in University (IRT13026) are gratefully acknowledged.

\section{Notes and references}

1 C. H. Tang, Y. P. Tang, J. G. Zhu, Y. W. Zou, J. H. Li and X. J. Ni, Nucl. Eng. Des., 2002, 218, 91-102.

2 S. Kazuhiro and U. Shohei, Nucl. Eng. Des., 2004, 233, 163172.

3 M. Masson, S. Grandjean, J. Lacquement, S. BourgJean, M. Delauzun and J. Lacombe, Nucl. Eng. Des., 2006, 236, 516-525.

4 M. IroIshihara, J. Sumita, T. Shibata, T. Iyoku and T. Oku, Nucl. Eng. Des., 2004, 233, 251-260.

5 G. Y. Zhang, M. F. Wen, S. W. Wang, J. Chen and J. C. Wang, J. Appl. Electrochem., 2016, 46, 1163-1176.

6 L. F. Tian, M. F. Wen and J. Chen, Electrochim. Acta, 2010, 56, 985-989.
7 L. F. Tian, M. F. Wen and J. Chen, J. Nucl. Mater., 2013, 432, 113-119.

8 Y. Qiu, S. Moore, R. Hurt and I. Külaots, Carbon, 2017, 111, 651-657.

9 Y. Qiu, F. Collin, R. H. Hurt and I. Külaots, Carbon, 2016, 96, 20-28.

10 Y. Qiu, F. Guo, R. Hurt and I. Külaots, Carbon, 2014, 72, 215223.

11 H. K. Jeong, Y. P. Lee, M. H. Jin, E. S. Kim, J. J. Bae and Y. H. Lee, Chem. Phys. Lett., 2009, 470, 255-258.

12 C. Zhang, W. Lv, X. Y. Xie, D. M. Tang, C. Liu and Q. H. Yang, Carbon, 2013, 62, 11-24.

13 C. K. Chua and M. Pumera, Chem. Soc. Rev., 2014, 43, 291-312. 14 V. G. Plotnikov, V. A. Smirnov, M. V. Alfimov and Y. M. Shul'Ga, High Energy Chem., 2011, 45, 411-415.

15 V. A. Smirnov, Y. M. Shul Ga, N. N. Denisov, E. I. Kresova and N. Y. Shul Ga, Nanotechnol. Russ., 2012, 7, 81-86.

16 K. Yin, H. T. Li, Y. D. Xia, H. C. Bi, J. Sun, Z. G. Liu and L. Sun, Nano-Micro Lett., 2011, 3, 51-55.

17 H. R. Thomas, S. P. Day, W. E. Woodruff, C. Vallés, R. J. Young, I. A. Kinloch, G. W. Morley, J. V. Hanna, N. R. Wilson and J. P. Rourke, Chem. Mater., 2013, 25, 3580-3588.

18 W. Lv, D. M. Tang, Y. B. He, C. H. You, Z. Q. Shi, X. C. Chen, C. M. Chen, P. X. Hou, C. Liu and Q. H. Yang, ACS Nano, 2009, 3, 3730-3736.

19 M. Z. Cai, D. Thorpe, D. H. Adamsonb and A. H. C. Schniepp, J. Mater. Chem., 2012, 22, 24992-25002.

20 C. Botas, P. Álvarez, C. Blanco, R. Santamaría, M. Granda, M. D. Gutiérrez, F. R. Reinoso and R. Menéndez, Carbon, 2013, 52, 476-485.

21 S. Eigler, C. Dotzer, A. Hirsch, M. Enzelberger and P. Müller, Chem. Mater., 2012, 24, 1276-1282.

22 W. K. Choi, B. J. Kim, E. Kim, S. H. Chi and S. J. Park, Nucl. Eng. Des., 2011, 241, 82-87.

23 E. S. Kim and H. C. No, J. Nucl. Mater., 2006, 349, 182-194.

24 L. Payne, P. J. Heard and T. B. Scott, PLoS One, 2015, 10, e143041.

25 A. Ganguly, S. Sharma, P. Papakonstantinou and J. Hamilton, J. Phys. Chem. C, 2011, 115, 17009-17019.

26 A. Lerp, H. Y. He, M. Forster and J. Klinowski, J. Phys. Chem. $B, 1998,102,4477-4482$.

27 H. Y. He, T. Riedl, A. Lerf and J. Klinowski, J. Phys. Chem., 1996, 100, 19954-19958.

28 D. W. Boukhvalov and M. I. Katsnelson, J. Am. Chem. Soc., 2008, 130, 10697-10701.

29 L. B. Casabianca, M. A. Shaibat, W. W. Cai, S. J. Park, R. Piner, R. S. Ruoff and Y. Ishii, J. Am. Chem. Soc., 2010, 132, 5672-5676.

30 X. F. Gao, J. Jang and S. Nagase, J. Phys. Chem. C, 2010, 114, 832-842.

31 R. Larciprete, P. Lacovig, S. Gardonio, A. Baraldi and S. Lizzit, J. Phys. Chem. C, 2012, 116, 9900-9908.

32 O. Akhavan, Carbon, 2010, 48, 509-519.

33 C. Mattevi, G. Eda, S. Agnoli, S. Miller, K. A. Mkhoyan, O. Celik, D. Mastrogiovanni, G. Granozzi, E. Garfunkel and M. Chhowalla, Adv. Funct. Mater., 2009, 19, 2577-2583. 
34 A. Bagri, C. Mattevi, M. Acik, Y. J. Chabal, M. Chhowalla and V. B. Shenoy, Nat. Chem., 2010, 2, 581-587.

35 H. C. Schniepp, J. L. Li, M. J. McAllister, H. Sai, M. HerreraAlonso, D. H. Adamson, R. K. Prud'Homme, R. Car, D. A. Saville and I. A. Aksay, J. Phys. Chem. B, 2006, 110, 8535-8539.

36 D. Zhan, Z. H. Ni, W. Chen, L. Sun, Z. Q. Luo, L. F. Lai, T. Yu, A. T. S. Wee and Z. Shen, Carbon, 2011, 49, 1362-1366.

37 A. Ambrosi, G. K. S. Wong, R. D. Webster, Z. Sofer and M. Pumera, Chem.-Eur. J., 2013, 19, 14446-14450.

38 Z. Sofer, P. Simek and M. Pumera, Phys. Chem. Chem. Phys., 2013, 15, 9257-9264.
39 S. Eigler, S. Grimm and A. Hirsch, Chem.-Eur. J., 2014, 20, 984-989.

40 Z. Sofer, O. Jankovský, P. Šimek, D. Sedmidubský, J. Šturala, J. Kosina, R. Mikšová, A. Macková, M. Mikulics and M. Pumera, ACS Nano, 2015, 9, 5478-5485.

41 C. G. Navarro, J. C. Meyer, R. S. Sundaram, A. Chuvilin, S. Kurasch, M. Burghard, K. Kern and U. Kaiser, Nano Lett., 2010, 10, 1144-1148.

42 X. F. Gao, J. Jang and S. Nagase, J. Phys. Chem. C, 2010, 114, 832-842.

43 X. J. Chen, D. L. Meng, B. Wang, B. W. Li, W. Li, C. W. Bielawski and R. S. Ruoff, Carbon, 2016, 101, 71-76. 